\title{
Business Case
}

\section{Dear Reader,}

the long-term future of the combustion engine will depend on the growing availability of sustainable energy sources. The use of carbon-neutral energy is fully in line with EU policy, which is aiming for a gradual reduction in greenhouse gas emissions of 80 to $95 \%$ by 2050 . As far as fuels are concerned, it is obvious that the challenges presented by renewable fuels which circulate $\mathrm{CO}_{2}$ can be resolved. A carbon-neutral solution can be achieved by using the $\mathrm{CO}_{2}$ produced in industrial processes (in particular steel and cement production) and in electricity generation as a raw material for the fuels. The recovery of $\mathrm{CO}_{2}$ from the air is also technically possible using low temperature heat. Sustainable electricity generated from wind or solar energy can be used to produce hydrogen by means of electrolysis or for endothermic processes (such as methane or methanol splitting or dry reforming). The hydrogen can reduce the $\mathrm{CO}_{2}$ created during the production of methanol and this can then be processed further.

However, the process engineering presents a much more serious problem. Obviously, the incentives needed to enlarge the production systems from a laboratory scale to an industrial scale are lacking. The obstacles referred to in this context include in particular the investment of several hundred million euros required and the lack of security in the planning process. In this respect, politicians could set an important example by making a clear commitment to this technology. But to focus only on this area would be too short-sighted. What is lacking is a clear business case which will allow the large amounts of money to be raised for investments that will only bring a return in the long term. Against the background of impending $\mathrm{CO}_{2}$ taxes, some car manufacturers are currently considering developing a business model based on carbon-neutral fuels. This could give the technology the long-awaited momentum necessary for large-scale implementation. Let's hope this happens.

Best regards,

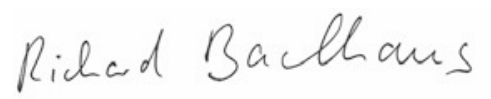

\section{Richard Backhaus}

Vice-Editor in Chief

Wiesbaden, 27 March 2015

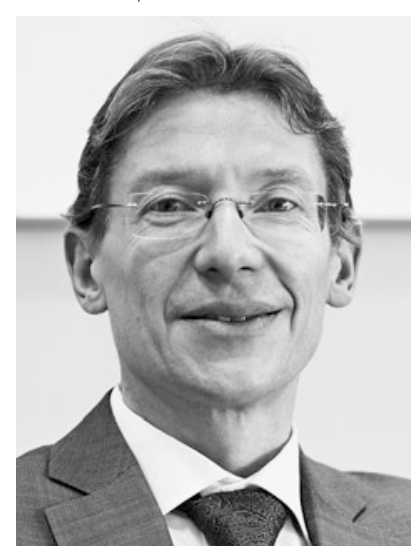

